\title{
Ricikan Sebagai Representasi Karakter Tokoh Pada Wayang Orang dan Upaya Pengembangannya
}

\section{Ricikan as Representation of Character Figure on Puppets and Its Development Efforts}

\author{
Asmaul Farida Azizi \\ Purwati Anggraini \\ Universitas Muhammadiyah Malang, Malang \\ asmaulazizi999@gmail.com
}

Riwayat Artikel: Dikirim 7 April 2020; Diterima 6 Juni 2020; Diterbitkan 30 Juni 2020

\begin{abstract}
ABSTRAK
Wayang orang merupakan kesenian drama klasik yang diadaptasi dari Wayang Purwa. Adaptasi tersebut termasuk kostum yang digunakan salah satunya adalah ricikan atau aksesoris pada wayang orang yang memiliki fungsi untuk menunjukkan karakter tokoh. Seiring perkembangan zaman, ricikan mengalami perkembangan dalam pengaplikasiaanya. Penelitian ini akan mendeskripsikan ricikan sebagai representasi karakter dan mendeskripsikan perkembangan ricikan pada pementasan wayang orang. Metode yang digunakan adalah metode metode deskriptif analitik. Pendekatan yang digunakan adalah pendekatan kualitatif. Sumber data pada penelitian ini adalah pengajar teater wayang orang. Data berupa gambar-gambar dan deskripsi lisan. Hasil dari penelitian ini adalah ricikan dapat digunakan sebagai representasi karakter tokoh melalui bentuk atau motif ricikan yang digunakan. Selain itu, pengembangan ricikan dapat ditemukan dari perubahan bahan pembuataannya dan beberapa ricikan digunakan sama rata tanpa memperhatikan karakter yang diperankan.
\end{abstract}

Kata kunci: Wayang Orang, Ricikan, Karakter, Pengembangan

\begin{abstract}
Puppet peo ple who are the embodiment of Wayang Purwa who use ricikan as accessories can show the character of the puppet that is played. The purpose of this study is to describe the story as a representation of character and describe the development of story in the puppet show. The method used is descriptive analytic method by revealing facts. The approach used is a qualitative approach. The data source in this study is a puppet theater instructor. Data in the form of pictures and oral descriptions. The results of this study are the instructions can be used as representations of the characters through the forms or motifs used by them.
\end{abstract}


In addition, the development of turnovers can be found from changes in the fabrication of the ingredients and some of them are used equally without regard to the character played.

Keywords: Puppet People, Ricikan, Character, Change

\section{PENDAHULUAN}

Kebudayaan merupakan suatu kebiasaan yang dilakukan oleh masyarakat tertentu. Kebudayaan di Indonesia memiliki banyak ragam karena banyaknya suku dan beragam keseinan. Kebudayaan dan kesenian adalah unsur penting, keduanya berperan untuk melengkapi sejalan dengan dinamika perkembangan masyarakat. Kesenian yang dinamis menjadi simbol dari kebudayaan yang juga dinamis dan sebaliknya, kebudayaan yang dinamis dapat menjadi simbol dari kreativitas dunia seni (Juliati, 2013:2). Kebudayaan dan kesenian yang terdapat dalam masyarakat perlu diapresiasi agar tetap lestari sebagai simbol eksistensi perkembangan masyarakat. Di Indonesia, masyarakat suku Jawa seringnya dianggap memiliki kesenian yang banyak dan beragam. Salah satunya adalah wayang orang.

Wayang orang merupakan salah satu bentuk kesenian yang berarti bagi kraton Yogyakarta. Hamengku Buwono I berhasil menciptakan wayang orang sebagai ritual kenegaraan pada sekitar tahun 1756 . Wayang orang digunakan sebagai ritual kenegaraan tersebut bertahan hingga tahun 1939 (Soedarsono, 1999:71). Wayang orang dulunya merupakan drama tari, namun sekarang lebih fokus pada kisahkisah Ramayana dan Mahabarata (Lindsay, 1991:83). Mahabarata merupakan pertunjukan wayang orang dengan kisah-kisah yang disertai dengan filosofi kehidupan yang dapat disebut sebagai wadah dari ajaran agama Hindu sehingga banyak diyakini oleh masyarakat Jawa dan Bali (Hadi, 2014:78).

Wayang orang merupakan adaptasi dari wayang purwa, atau biasa disebut wayang kulit punwa. Wayang orang adalah sebuah bentuk drama tradisional yang dilustrasikan oleh gerak tari disertai pocapan atau dialog (Paneli, 2017:78). Dengan begitu, wayang orang tentu memiliki kostum yang sama dengan wayang purwa. Hal tersebut meliputi watak, suara, riasan wajah, kostum berupa pakaian hingga aksesoris yang digunakan. Pada awal dibentuknya wayang orang pada masa Kraton Yogyakarta, kostum wayang orang dibuat oleh Kanjeng Jayadipura (Soedarsono, 1990:201). Aksesoris dibuat sedemikian rupa oleh Kanjeng Jayadipura dengan mengacu pada relief-relief yang terukir pada candi-candi di Pulau Jawa. Sampai saat ini, terdapat lakon wayang orang yang masih berjaya yaitu Wayang Orang Sriwedari yang berada di Surakarta yang berada di bawah pemerintah untuk menjaga eksistensinya (Kusharyani, Santoso, \& Wisnaeni, 2016:64)

Namun dengan kemajuan zaman, terdapat perubahan yang terjadi pada kostum pemain wayang orang. Perubahan tersebut termasuk pada ricikan yang mereka gunakan. Selain riasan, aksesoris atau ricikan juga menunjukkan identitas 
pemain termasuk karakter tokoh wayang yang diperankan. Dalam pewayangan, tentu ada perbedaan penggunaan aksesoris. Contohnya untuk membedakan tokoh bangsawan dengan rakyat biasa; tokoh kesatria dengan tokoh bangsawan; begitu pula tokoh kesatria dengan patih dan karakter yang mereka miliki. Riasan untuk tokoh antagonis dengan protagonis harus diperhatikan agar tidak ada kesalahpahaman terhadap pemaknaan karakter tokoh.

Karakter pada wayang orang tidak hanya dapat diketahui dengan dialog yang diucapkanoleh pemeran wayang. Sebelum pemeran melakukan dialog, penonton dapat mengetahui karakter tokoh dengan riasan maupun kostum yang dikenakan. Namun pemahaman mengenai hal tersebut masih kurang didukung dengan sedikitnya pementasan wayang orang pada zaman sekarang.

Penelitian yang sebelumnya mengenai ricikan wayang orang terdapat dalam skripsi yang ditulis oleh Prasetyo, berjudul Komparasi Kostum Gathutkaca dalam Wayang Wong dan Wayang Purwa Gaya Yogyakarta. Pada hasil penelitian ditemukan perbedaan kostum termasuk aksesoris atau ricikan. Kostum pada Gathutkaca lebih lengkap pada wayang purwa daripada wayang orang, namun kostum untuk wayang orang tetap dibuat berdasarkan wayang purwa. Terdapat cara pememakaian kostum yang berbeda antara wayang purva dan wayang orang. Penelitian kostum tersebut juga menemukan perbedaan nama dari kostum yang digunakan oleh tokoh Gathutkaca (Prasetyo, 2012). Selain itu, terdapat penelitian yang disusun oleh Kurniyawan dan Utina yang berjudul Makna dan Fungsi Ricikan pada Busana Wayang Wong Gaya Surakarta. Hasil penelitian tersebut adalah ricikan pada busana Wayang Wong gaya Surakarta bermotif tumbuhan dan hewan. Motif tumbuhan meliputi: bunga, akar-akaran, lung-lungan, buah, dan daun. Motif hewan meliputi: hewan besar, bersayap, dan mitologi. Makna simboli ricikan dapat diartikan dari nama dan motif dalam ricikan. Ricikan busana Wayang Wong gaya Surakarta sebagian besar memiliki fungsi sebagai aksesoris atau pelengkap (Kurniyawan \& Utina, 2019:177).

Hasil penelitian terdahulu menunjukkan bahwa terdapat perbedaan kostum dan ricikan yang digunakan dalam wayang orang dipengaruhi oleh kreativitas perajin serta dan keberagaman permintaan oleh pembeli. Hal tersebut menimbulkan nilai estetika yang berbeda dari kostum dan ricikan sebelumnya. Selain itu, kostum wayang orang didesain lebih sederhana dari wayang purva karena adanya prinsip mengedepankan kesederhanaan dan penjiwaan pemeran wayang. Dengan demikian, tidak menutup kemungkinan ricikan wayang yang berada di Kediri mengalami perkembangan. Penelitian ini bertujuan untuk mendeskripsikan ricikan sebagai representasi karakter dan pengembangan ricikan sebagai aksesoris pada wayang orang.

\section{METODE}

Metode penelitian yang digunakan dalam penelitian ini adalah metode deskriptif analitik dengan mengungkapkan fakta-fakta sesuai yang didapatkan di lapangan. Lokasi penelitian berada di Kediri, Jawa Timur. Pendekatan yang 
digunakan adalah pendekatan kualitatif dengan data berupa ucapan atau kata-kata dan gambar (Juliati, 2013:3). Sumber data pada penelitian ini adalah pengajar teater wayang orang di sekolah menengah pertama dan sanggar wayang orang di Kediri. Data yang didapatkan berupa foto dokumentasi, catatan observasi, dan hasil wawancara. Teknik pengumpulan data dilakukan dengan wawancara dan observasi. Teknik analisis data dilakukan dengan tiga tahapan yaitu reduksi data, penyajian data, dan kesimpulan dari data yang dianalisis.

\section{HASIL DAN PEMBAHASAN}

\section{Peran Ricikan sebagai Representasi Karakter tokoh pada Wayang Orang}

Pada pementasan wayang orang, aktor tidak hanya tampil dengan pakaian biasa. Penggunaan kostum serta riasan yang mendukung sangat diperlukan. Pada wayang orang terdapat ricikan sebagai pendukung peran agar memiliki visual yang sama dengan wayang kulit sebagai pokok terciptanya wayang orang. Ricikan membantu penonton untuk membedakan antara tokoh satu dengan tokoh lain dan merupakan cerminan karakter atau watak tokoh wayang orang. Contoh Arjuna dengan Kresna tentu beda visual yang ditunjukan. Berikut pembahasan aksesoris atau ricikan pada wayang orang.

\section{Sumping}

Sumping adalah perhiasan yang dikenakan di telinga. Sumping biasa bermotif makara atau makhluk mitologi ikan berkepala gajah. Sumping umumnya berfungsi sebagai pelindung telinga pemakainya (Setyowati \& Lutfiati, 2014). Menurut narasumber, sumping dari dulu terbuat dari kulit, dengan begitu kesan seni yang ditimbulkan lebih kuat. Sumping juga digunakan dalam riasan pengantin adat pernikahan Ponoragan Kabupaten Ponorogo. Sumping melati dengan keseluruhan badan sumping ditutupi bunga melati bermakna kesucian niat dari hati yang tulus dan digunakan oleh pengantin laki-laki (Dewi, 2017:115).

Sumping hanya dipakai oleh para bangsawan. Tokoh bawahan seperti Punakawan tidak memakai sumping. Tokoh yang memakai sumping antara lain Arjuna, Abimanyu, dan Gathutkaca. Pada Arjuna, sumping digunakan untuk menyimbolkan bahwa Arjuna termasuk dalam kasta bangsawan serta kesatria yang hebat dengan nama sumping yang dikenakan adalah sumping surengpati (Devianti \& Amzy, 2019:246). Sumping yang Arjuna kenakan bernama pari sumub dan hanya dia yang memakai sumping tersebut membuktikan bahwa Arjuna adalah kesatria yang jujur.

Abimanyu adalah anak dari Arjuna dan Sumbadra. Sumping yang Abimanyu kenakan bermakna bahwa dia adalah seorang bangsawan keturunan dari ayah dan ibunya. Baimanyu dikenal sebagai sosok yang tidak mengenal rasa takut sebagai kesatria, sesuai kasta yang dia miliki. Gathutkaca juga menggunakan sumping, sumping yang ia kenakan adalah sumping makara, menyimbolkan bahwa Gathutkaca meruapakan keturunan bangsawan dari ras Rakshasa yang memiliki kesaktian yang tidak terkalahkan. 
Menurut narasumber, pembeda antara tokoh dengan karakter antagonis dan protagonis dapat dilihat dari warna yang digunakan pemain. Namun tidak ada perbedaan dalam penggunaan sumping pada pemain. Gambar di bawah ini adalah termasuk sumping makara, umumnya warna yang digunakan pada sumping adalah warna emas. Ada beberapa sumping wayang orang, antara lain; sumping gajah ngoling, sumping sekar kluwih, sumping rajamala, dan sumping waderan. dan sumping makara. Makara merupakan perwujudan hewan mitologi yaitu gabungan dua hewan (naga dan ikan). Motif tersebut berarti menghalau gangguan batin pada manusia. Pemakai sumping tersebut diharapkan jauh dari gangguan batin seperti angkuh, egois, dan culas sebagai bangsawan yang menjadi teladan dalam tutur dan tindakannya.

\section{Gambar 1:}

Sumping

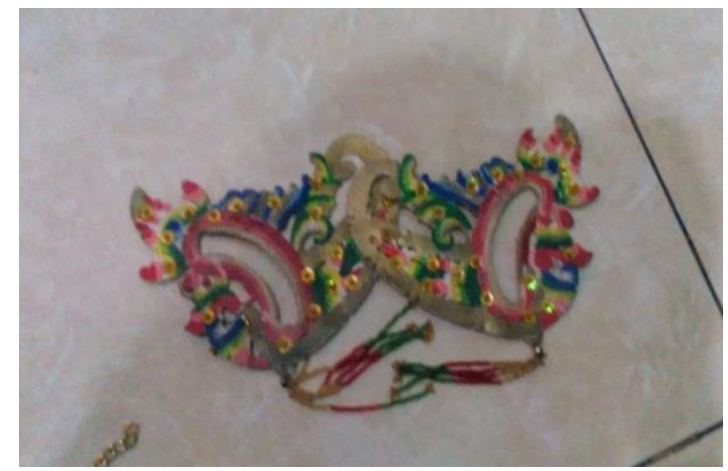

Sumber: Dokumentasi Pribadi

\section{Sampur atau Selendang}

Sampur atau selendang ini dipakai oleh pemeran wayang orang kecuali Punakawan. Sampur digunakan pada bagian pinggang dan digunakan untuk menari karena kesenian wayang orang juga menunjukkan adegan menari dalam lakonnya. Tarian dalam wayang merupakan representasi dari peristiwa yang terjadi dalam alur cerita seperti latar belakang cerita dan tema (Sumiati, 2012:52). Menurut narasumber, bahan pembuatan sampur dibebaskan menggunakan berbagai macam jeis kain. Umumnya warna yang digunakan adalah hijau, kuning, dan merah dengan hiasan manik-manik di ke dua ujung sampur.

Tokoh dalam cerita Mababarata, terdapat sampur warna hitam yang hanya dikenakan oleh Anoman. Warna hitam tersebut sebagai identitas diri dan karakter tunduk patuh serta cerminan kekuatan sakti yang dia miliki.

Menurut narasumber, penggunaan warna pada sampur tidak membedakan karakter pada wayang orang kecuali Anoman, karena wayang orang adalah sebuah seni pertunjukan yang melibatkan tarian. Sehingga para tokoh dalam wayang orang menggunakan sampur atau selendang sebagai atribut menari. Narasumber mengemukakan bahwa hiasan yang dipasangkan pada sampur tidak 
memiliki makna secara gamblang. Hiasan tersebut hanya menambah kesan cantik pada selendang yang digunakan. Namun, dalam adat pernikahan Ponoragan Kabupaten Ponorogo, sampur digunakan dengan sebutan stagen cinde sebagai makna manusia dapat menata badan dan perilakunya (Dewi, 2017:114). Menurut makna tersebut, dalam pewayangan, pemeran wayang orang secara tidak langsung harus mampu menata badan dan perilakunya saat menari agar tetap elok ataupun teratur walaupun tarian tersebut berlatar kesedihan atau peperangan.

Gambar 2:

Sampur atau Selendang

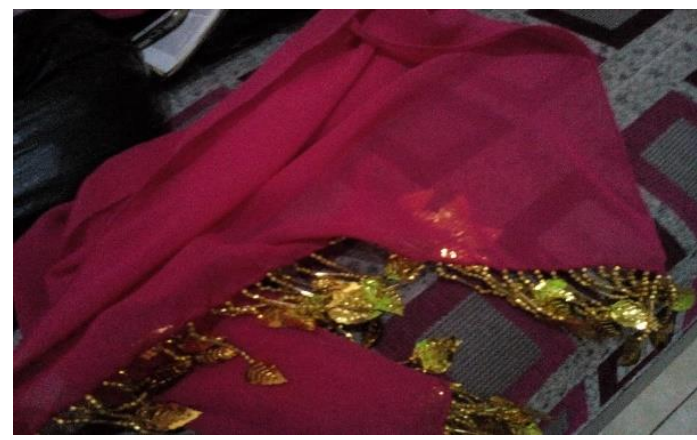

Sumber: Dokumentasi Pribadi

\section{Kelat Bahu}

Kelat bahu digunakan di tangan, diikatkan pada lengan bagian atas. Kelat bahu terbuat dari kulit dengan hiasan manik-manik emas. Bahan asli pembuatan kelat bahu adalah logam mulia seperti emas. Namun zaman sekarang kelat bahu dibuat dari kulit yang dapat dicat emas maupun dihiasi oleh manik-manik warna emas. Kelat bahu berasal dari kata 'kelat' yang artinya melekat, sedangkan arti keseluruhannya adalah melekat di bahu.

Kelat bahu menurut narasumber dipakai oleh laki-laki dan perempuan, tetapi berbeda bentuk. Kelat bahu digunakan oleh wayang yang antara lain seorang bangsawan dan kesatria. Kelat bahu tidak digunakan oleh tokoh bawahan. Mereka adalah bangsawan dan kesatria yang berkarakter rendah hati dan mementingkan kekayaan batin. Kelat bahu ini hanya mereka gunakan pada saat muda contohnya pada pasangan Arjuna dan Sembadra. Kelat bahu juga digunakan tokoh dengan karakter antagonis sebagai simbol kebangsawanan maupun kesaktian yang mereka miliki. Salah satunya adalah kelat bahu candrakirana yang hanya digunakan tokoh Werkudara dan Anoman dengan simbol rembulan. Makna dari kelat bahu candrakirana tersebut adalah pemakai kelat bahu memiliki banyak pengetahuan yang benar dan ditujukan hanya untuk diamalkan pada sesama. Kelat bahu yang digunakan tokoh wayang putra yang lain yaitu kelat bahu yang digunakan bermotif makara atau gabungan dua hewan mitologi Hindu yang umumnya berwarna emas, sedangkan untuk tokoh perempuan pada dasarnya menggunakan bentuk yang sama yaitu burung merak dan tidak membedakan karakter yang mereka miliki. 
Gambar 3:

Kelat Bahu untuk Perempuan

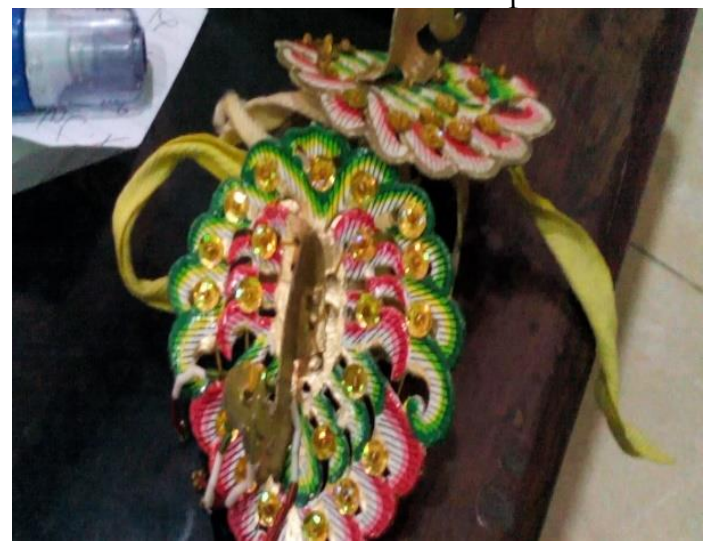

Sumber: Dokumentasi Pribadi

Perbedaan antara kelat bau laki-laki dan perempuan adalah bentuknya. Kelat bahu untuk perempuan (lih. Gambar 3) berbentuk seperti daun dan terdapat ornamen yang timbul pada tengah kelat bahu yaitu burung merak. Burung merak pada kelat bahu perempuan menyimbolkan keindahan dan keangguanna perempuan melalui ekor burung merak yang merekah.

Gambar 4:

Kelat Bahu untuk Laki-laki

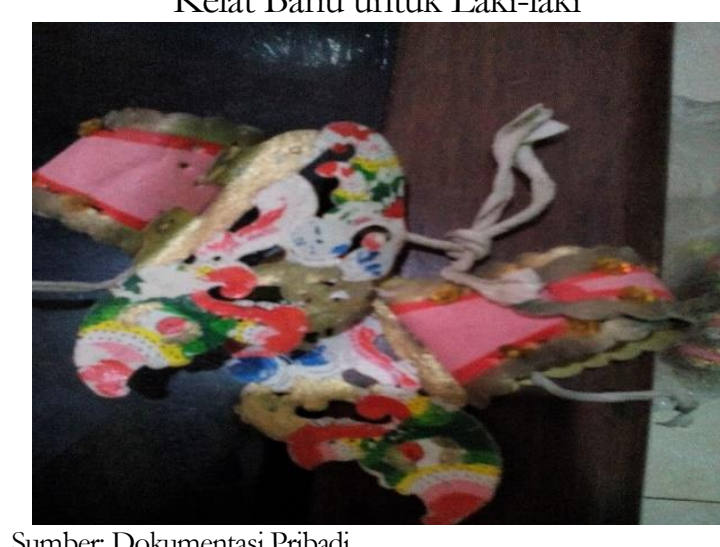

Sumber: Dokumentasi Pribadi

Kelatbahu yang digunakan laki-laki berbentuk garuda mungkur dengan sisi yang panjang yang dilingkarkan pada lengan lalu diikat. Motif garuda mungkur bermakna mendatangkan keselamatan dan keberuntungan. Sedangkan untuk garuda sendiri bermakna kepemilikian intelektual yang tinggi pada pemakainya. Kelat bahu dipakai dengan dihadapkan ke belakang sedikit sebagai simbol penolak bahaya (Sunaryadi, 2013:274). Kelat bahu yang dikenakan Werkudara memiliki 
motif belahan buah manggis bernama kelat bahu Candrakirana. Sesuai dengan karakter yang Werkudara yaitu manusia yang tidak mengingkari janji yang telah dibuat. Selain Werkudara tokoh lain yang menggunakan adalah Anoman sebagai bagian dari titisan dewa yang juga termasuk kesatria bijaksana dalam pewayangan.

\section{Uncal}

Uncal adalah aksesoris yang menggelantung di antara dua kaki yang menggunakannya dengan tali yang ujungnya berumbai dan biasanya digunakan sebagai senjata yang cara pakainya dengan dilempar. Aksesoris ini hanya dipakai oleh tokoh laki-laki, dengan karakter protagonis maupun antagonis. Terdapat dua jenis uncal yaitu uncal kencana dan uncal wastra. Uncal wastra digunakan oleh tokoh yang gagah atau rasaksa seperti Rahwana. Namun untuk Gathutkaca yang memiliki karakter baik hati menggunakan uncal yang sama dengan Rahwana, untuk menunjukkan bahwa Gathutkaca adalah tokoh dengan karakter gagah sebagai keturunan dari raksasa. Sedangkan uncal kencana digunakan oleh tokoh putra yang halus yang memiliki kepribadian baik seperti Arjuna, Abimanyu, dan Kresna (Prasetyo, 2012: 56).

Warna yang digunakan dalam pembuatan uncal umumnya berwarna emas dengan warna tengah yang bermacam-macam. Ujung yang berumbai umumnya memnggunakan warna yang mencolok seperti digambar warna kuning dan merah. Bentuk uncal tidak pernah berubah, selalu ada bagian pipih dengan ujung berumbai.

Gambar 5:

Uncal dan Badhong

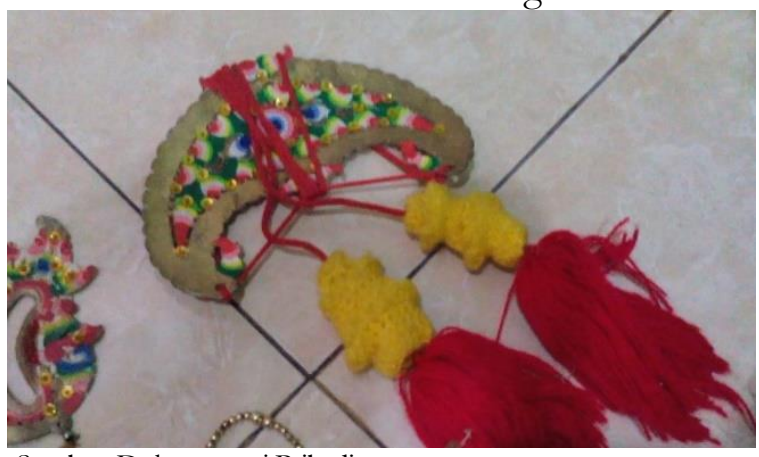

Sumber: Dokumentasi Pribadi

\section{Jamang}

Terdapat dua jenis jamang yang dibuat oleh pembuat kostum wayang orang, Kanjeng Jayadipura. Jamang tersebut adalah jamang mangkara yang dipakai oleh Krisna. Briswara, Gathutkaca dan tokoh pendukung lain dan jamang januran yang dipakai oleh para Pandhawa. Jamang mangkara memiliki memiliki satu bentuk daun di tengah-tengah dahi dan bagian belakang dihiasi dengan bentuk daun berjumlah 13 daun dibentuk berkelilingdengan ukiran makara sebagai ujung (Soedarsono, 1990). 
Jamang digunakan pada tokoh yang memiliki kasta sebagai kesatri, bangsawan, maupun keluarga kerajaan (Soedarsono, 1990). Narasumber hanya memiliki satu model jamang yang dapat digunakan pada seluruh tokoh. Terbuat dari plasmen dan lebih cerah karena dicat warna emas sesuai dengan pakem. Hanya saja ukiran, hiasan, maupun permata pada jaman tidak tergantung pada pakem seperti yang di buat oleh Kanjeng Jayadipura. Hanya diberi permata imitasi di tengah serta permata yang memutari jamang. Tokoh pada wayang yang menggunakan jamang januran adalah Bima, Arjuna, Abimanyu, Yudhistira, dan Nakula dengan pengunaan jamang januran yang berbeda.

Jamang dengan motif daun kelapa dengan bunga pundhak setegal atau biasa disebut jamang januran pundhak setegal yang biasa dikenakan oleh Werkudara dan Anoman sebagai simbol karakter kesatria yang jujur, teguh dengan pendiriannya, dan suci. Jamang biasanya tersusun dua hingga tingga sebagai simbol keagungan atau simbol seorang raja. Tokoh Gathutkaca menggunakan jamang cringih susun tiga sebagai simbol kesatri namun memiliki derajat yang sama dengan para raja (Prasetyo, 2012: 40).

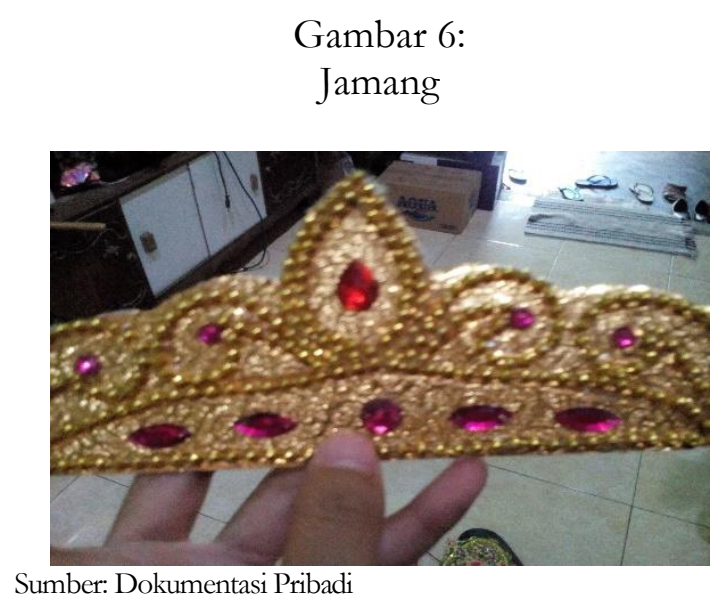

\section{Irah-irahan}

Irah-irahan adalah hiasan yang dipakai di kepala. Irah-irahan biasa dibuat dari beludru. Banyak tokoh wayang menggunakan irah-irahan. Biasanya irahirahan dan jamang tidak dibuat secara terpisah, tetapi jamang sudah melekat pada irah-irahan dengan sanggul disetiap irah-irah.

Irah-irahan ketu biasanya dipakai oleh para patih. Bentuknya sederhana dan biasa disebut ketu udheng atau trombosan. Bentuknya hampir mirip dengan kopiah kain. Tokoh yang menggunakan irah-irahan ini memiliki perubahan karakter. Contoh Sengkuni sebagai path yang baik mengabdi pada Kresna. Namun dengan wataknya yang serahkah, dia mampu menghasut keluarga kerajaan hingga terjadi perang. Begitu pula dengan Aswatama, patih yang sakti dan sangat kuat mendapat hukuman karena perbuatannya yang berhasil membunuh lima Pandawa. Hukuman tersebut adalah hidup abadi tanpa adanya rasa kasih sayang. 
Lengkungan atau gelungan pada irah-irahan juga menyimbolkan karakter tokoh wayang. Gelung supit urang pada tokoh Anoman menyimbolkan karakter pribadi yang sederhana dan rendah hati. Irah-irahan biasa disebut mekhuta untuk menyimbolkan pemimpin atau raja, contoh tokoh yang mengenakan mekutha adalah Krenas dan Rahwana.

Gambar 7:

Irah-irahan untuk Arjuna

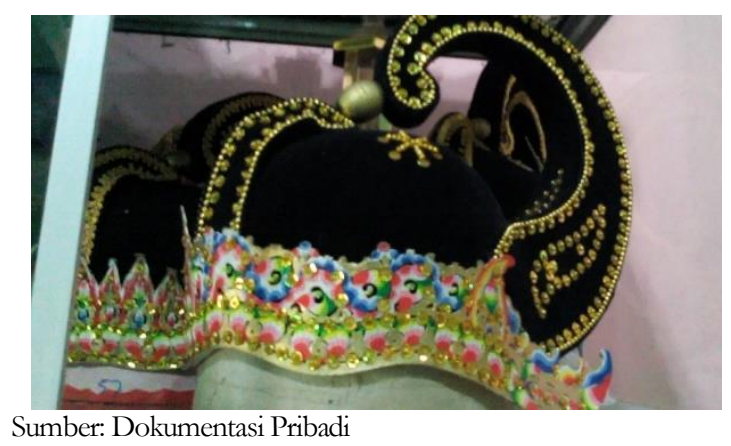

Arjuna memiliki irah-irahan yang khusus dipakai olehnya dengan jamang januran kbudup turi. Gelungan supit urang yang Arjuna kenakan menyimbolkan rendah hati yang dia miliki, sama seperti Anoman.

Gambar 8:

Irah-irahan Gathutkaca

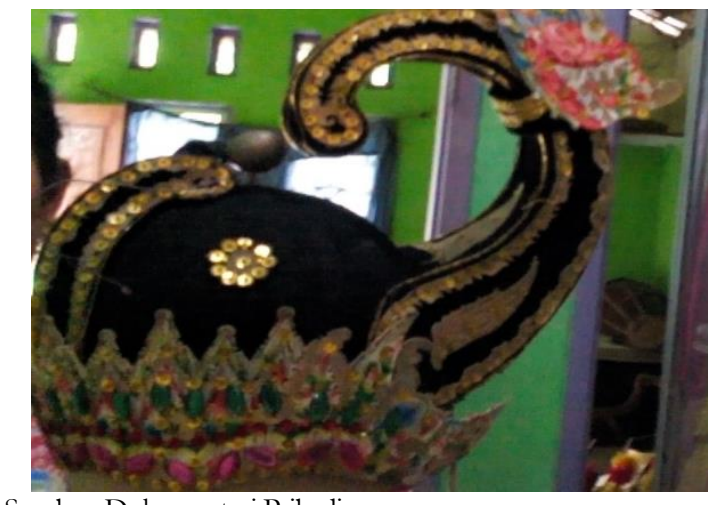

Sumber: Dokumentasi Pribadi

Pada irah-irahan milik Gathutkaca terdapat jamang susun 3. Gelungan pada irah-irahannya disebut sebagai gelung supit urang. Pada gelungan terdapat garuda mungkur yang melingkar. Garuda mungkur pada irah-irahan Gathutkaca memiliki simbol sebagai karater kesatria yang gagah berani dan sangat kuat didukung dengan kekuatan yang dia miliki sejak kecil. 


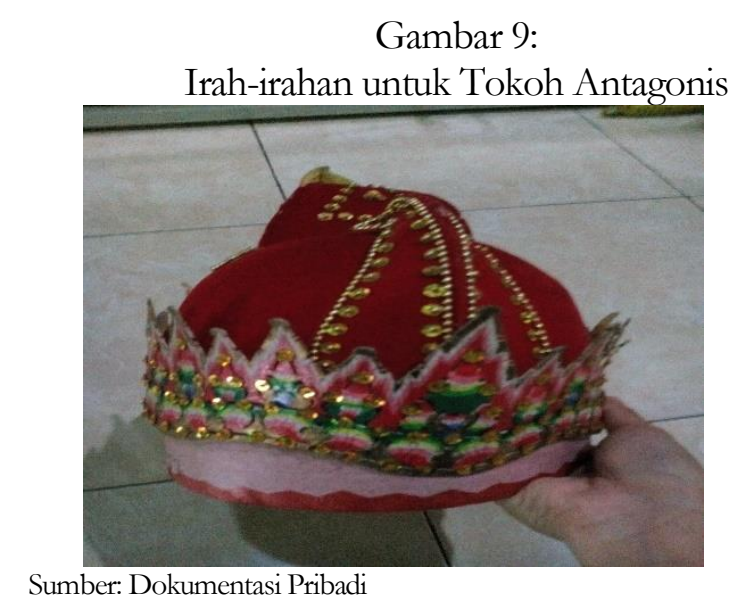

Narasumber mengatakan bahwa untuk membedakan tokoh protagonis dan antagonis dapat dibedakan melalui warna. Tokoh protagonis menggunakan kostum dengan warna seperti hitam, ungu, maupun hijau. Tokoh antagonis menggunakan irah-irahan berwarna merah menandakan bahwa dia tokoh yang jahat didukung dengan riasan wajah serta suara yang besar. Warna merah dalam wayang orang memiliki makna tokoh yang agresif (Sumarni, 2001:44). Gambar 9 merupakan jenis irah-irahan topong yang berbentuk bulat dan pendek dan biasa digunakan oleh tokoh Adipati Karna. Adpiati Karna memiliki sifat angkuh namun juga dermawan.

\section{Binggel atau Kroncong}

Binggel atau kroncong merupakan aksesoris yang bentuknya sama dengan gelang namun dikenakan di pergelangan kaki. Aksesoris ini berwarna emas. Terdapat beberapa jenis binggel yaitu Gelang Binggel Rangkep yang biasa digunakan oleh patih seperti Pragota yang merupakan patih Prabu Baladewa. Selain itu terdapat jenis Gelang Binggel Rangkep Clumpringan, dikenakan khusus tokoh Narakasura yaitu raja raksasa. Binggel digunakan dengan makna kedudukan yang dimiliki oleh wayang. Pada dasarnya penggunaan binggel tersebut dapat ditemui pada wayang kulit, wayang orang sekarang cukup menggunakan binggel dengan warna emas yang menambah estetika aktor ketika pentas. 


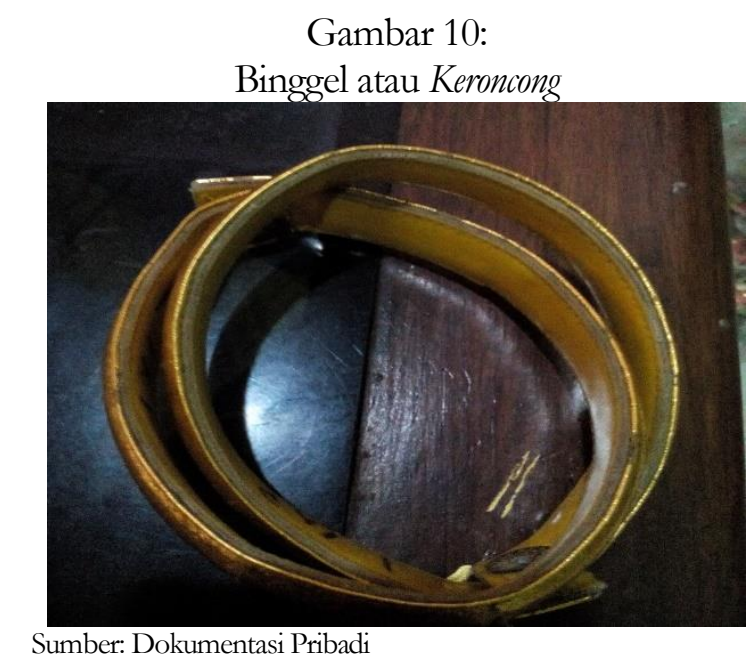

\section{Pengembangan Ricikan sebagai Aksesoris pada Wayang Orang}

Ricikan atau pada aksesoris wayang orang berubah seiring perkembangan zaman. Perubahan tersebut meliputi bahan yang digunakan untuk membuat aksesoris. Banyak akseosris wayang seperti sumping, ulat bahu, endhong terbuat dari kulit. Kulit yang biasa digunakan adalah kulit sapi atau kerbau. Dengan alasan kemudahan mendapatkan bahan dan praktis, pengrajin menggunakan plasmen dalam pembuatan aksesoris.

Irah-irahan dibuat dengan lapisan beludru. Namun sekarang menggunakan bahan yang mudah didapat dengan harga terjangkau. Jamang dan mahkota yang dulunya terpisah, sekarang didesain menyatu antara jamang dan mahkota dengan sebutan irah-irahan. Ricikan pada busana wayang wong dibuat mengikuti berkembangnya zaman. Ricikan dibuat sesuai kreativitas pengrajin yang mengikuti perkembangan zaman, pengrajin dapat mengedepakan estetika ricikan tanpa terlalu kepada makna yang ada pada setiap ricikan. Selain itu, terdapat permintaan pembeli yang semakin beragam dan dapat mengesampingkan keaslian ricikan yang telah dirancang sejak zaman dahulu (Kurniyawan \& Utina, 2019:184).

Perbedaan juga dapat ditemukan pada pengunaan ricikan khususnya jamang yang dahulu ada beberapa bentuk, serta setiap bentuk digunakan oleh tokoh yang berbeda. Zaman sekarang dibentuk sama meski yang menggunakan berbeda-beda, dihias dengan permata imitasi dan warna yang tetap yaitu emas. Meskipun penggunaan jamang sama rata antar tokoh, namun tidak memengaruhi tampilan wayang orang di panggung. Tokoh tetap dapat dibedakan melalui riasan wajah yang digunakan. Selain jamang, uncal yang dulunya digunakan sebagai senjata, kini pada wayang orang digunakan sebagai aksesoris semata. Bahan pembuatan jaman dahulu adalah besi, namun seiring waktu jamang dapat dibuat dengan kuliat atau bahan yang lebih ringan dan lentur yaitu plasmen.

Dari sudut pandang narasumber sendiri, ricikan atau aksesoris wayang perlu diketahui oleh pemeran wayang orang sendiri, dikarenakan terdapat aksesoris 
atau ricikan yang hanya digunakan beberapa tokoh saja seperti untuk irah-irahan. Di setiap itah-irahan ada jamang yang hanya ada beberapa tokoh wayang yang menggunakan. Pembedaan penggunaan ricikan juga harus diiringi oleh kemampuan tata rias yang mendukung visualisasi karakter tokoh. Dari segi keindahan, narasumber mengungkapkan bahwa bahan dari plasmen lebih indah dan menarik, namun kesan klasik lebih terlihat pada penggunaan bahan dari kulit.

\section{KESIMPULAN}

Drama tradisional wayang orang memiliki aksesoris dengan berbagai makna. Makna tersebut dapat dilihat dari warna, bentuk, serta ukiran yang etrdapat dalam aksesoris tersebut. Selain itu, melalui aksesoris atau ricikan tersebut karakter tokoh yang diperankan dapat dikenali dengan mudah. Terdapat pula aksesoris yang hanya dikenakan oleh tertentu untuk menyimbolkan kekuatan atau karakter tokoh wayang.

Aksesoris atau ricikan pada wayang orang mengalami perubahan dari bahan serta segi kepraktisan. Kostum terutama ricikan atau aksesoris memiliki tugas sebagai tanda watak atau karakter tokoh pada pementasan wayang orang. Sehingga penonton -terutama bagi yang menguasai kesenian wayang dapat mebedakan tokoh satu dengan tokoh yang lain terutama dari ricikan yang digunakan. Masyarakat awam dapat mebedakan peran antagonis dan protagonis dari riasan serta warna ricikan yang digunakan pemeran wayang orang. Ricikan sendiri sebagai pendukung visualisasi pada wayang orang menyimbolkan berbagai karakter yang dimiliki setiap tokoh yang diperankan. Selain itu, ricikan mengalami perubahan pada bahan pembuatan, disebabkan oleh perkembangan bahan, kemudahan produksi, segi praktis, dan keawetan.

\section{DAFTAR PUSTAKA}

Devianti, N., \& Amzy, N. (2019). Karakter Tokoh Arjuna dalam Buku Ilustrasi Lakon Wayang Arjuna Wiwaha. Visual Heritage: Jurnal Kreasi Seni Dan Budaya, 1(03), 242-250.

Dewi, D. S. (2017). Pernikahan Ponoragan di Kabupaten Ponorogo,Jawa Timur ( Kajian Semiotika Visual ) Semiotika visual pada dasarnya merupakan sebuah bidang studi semiotika yang secara khusus menaruh minat pada penyelidikan terhadap segala jenis makna yang disampaikan mela. JADECS, 2(2), 107-127.

Hadi, S. (2014). Konsep Apik Dalam Koreografi Wayang Babar. Jurnal Kawistara, 4(1), 77-86. https:/ / doi.org/10.22146/kawistara.5234

Juliati, A. (2013). Pengembangan Kesenian Wayang Orang Industri Kreatif Dalam Paguyuban Kapribaden Kawruh Kasepuhan Pamencar Pramana Nyata di Desa Sragi Kecamatan Talun Kabupaten Blitar.

Ricikan Sebagai Representasi Karakter Tokoh... 
Kurniyawan, A. W., \& Utina, U. T. (2019). Makna dan Fungsi Ricikan pada Busana Wayang Wong Gaya Surakarta. Jurnal Seni Tari, 8(2), 176-185.

Kusharyani, M., Santoso, B., \& Wisnaeni, F. (2016). Eksistensi Dan Perlindungan Wayang Orang Sriwedari Surakarta Ditinjau Dari Aspek Hukum Hak Cipta. Law Reform, 12(1), 60-72. https://doi.org/10.14710/lr.v12i1.15841

Lindsay, J. (1991). Klasik, Kitsch, Kontemporer: Sebuah Studi tentang Seni Pertunjukan Jawa. Yogyakarta: Gadjah Mada University Press.

Paneli, D. W. W. (2017). Transformasi Pertunjukan Wayang Orang Komunitas Graha Seni Mustika Yuastina Surabaya. Journal of Art, Design, Art Education And Cultural Studies (JADECS), 2(2), 74-97.

Prasetyo, N. S. (2012). Komparasi Kostum Gathutkaca dalam Wayang Wong dan Wayang Purwa Gaya Yogyakarta. Universitas Negeri Yogyakarta.

Setyowati, I., \& Lutfiati, D. (2014). Riasan Wayang Wong Tokob Rabwana Dan Anoman Kisah Ramayana Di Taman Hiburan Rakyat Surabaya. Jurnal Tata Rias, 3(3).

Soedarsono. (1990). Wayang Wong: The State Ritual Dance Drama In The Court of Yogyakarta. Yogyakarta: Gadjah Mada University Press.

Soedarsono. (1999). Seni Pertunjukan Indonesia di Era Globalisasi. Jakarta: Direktorat Jendral Pendidikan Tinggi.

Sumarni, N. S. (2001). Warna, Garis, dan Bentuk Ragam Hias. Harmonia, 2(3), 37-49. https://doi.org/https://doi.org/10.15294/harmonia.v2i3.860

Sumiati, L. (2012). Tari Wayang Karakter Satria Ladak. Panggung, 22(1), 52 66. https://doi.org/10.26742/panggung.v22i1.35

Sunaryadi. (2013). Aksiologi Tari Bedhaya Kraton Yogyakarta. Jurnal Kawistara, 3(3), 263-276. https://doi.org/10.22146/kawistara.5221 